\title{
Effect of Egg Storage Length on Hatchability and Survival of Koekoek Chickens
}

\author{
Setsumi Motsoene Molapo*, Motselisi Mahlehla, Paseka Pascalis Kompi, and Monaheng Taoana \\ Department of Animal Science, National University of Lesotho, P.O. Roma 180, Lesotho \\ *Corresponding author's Email: sm.molapo@nul.ls; ORCID: 0000-0002-4426-8901
}

Received: 31 Dec. 2020

Accepted: 07 Feb. 2021

\begin{abstract}
Chicken production plays a major in the livelihood of rural people due to the provision of eggs and meat which are high sources of protein. This calls for sustainable production of chickens through strategies aimed at improving the hatchability of eggs and survival of chickens. Therefore, the present study was conducted to determine the effect of egg storage length on egg hatchability and survival of the Koekoek chickens. A total number of 270 eggs were divided into three treatment groups, and the eggs of each group were stored for 3, 7, and 11 days before incubation. Each treatment consisted of three replicates. The General Linear Model procedure was used to analyze the data. The eggs that were stored for three days before incubation had a higher hatching percentage, compared to those that were stored for 7 and 11 days before incubation. Storing eggs for few days before incubation resulted in reduced embryonic mortality rate and lower mortality of chickens during the first seven days after hatching. Based on these results, is recommended that Koekoek chicken eggs should be stored for three days before incubation to maximize hatchability and survival of chickens before the age of seven days.
\end{abstract}

Keywords: Eggs, Storage, Embryo mortality, Hatchability, Koekoek chicken

\section{INTRODUCTION}

The small-scale poultry production system is the main source of income and protein for the majority of poor people, especially in rural areas (Wong et al., 2017). The demand for Koekoek chickens is high and their performance is better than indigenous breeds (Yirgu et al., 2019). They are one of the best-suited chicken breeds for a free-range environment under the rural communities setting and it is unnecessary to confine them in a shelter (Belay et al., 2018). The average egg production performance of the Koekoek chickens was reported 176 per year with an average egg weight of 45.33 grams (Abadi et al., 2020).

However, Molapo and Kompi (2015) highlighted that the majority of farmers rearing Koekoek chickens depend on hatcheries for the supply of one-day-old chickens while a small number of farmers hatch their chickens through natural incubation. Therefore, Boleli et al. (2016) stated that the continuous supply of chicken meat and eggs in the market is influenced by increasing the hatchability of healthy chickens that would survive under different rearing field conditions. On the other hand, Salamon (2020) emphasized that the storage conditions of the eggs before incubation have a significant effect on hatchability. Among these factors, Nasri et al. (2019) emphasized that the pre-incubation egg storage time has an impact on the hatching percentage of eggs. Therefore, to have an improved hatching percentage, eggs that are unsuitable for incubation should not be used for hatching purposes but could be used as a source of protein for families. Storage of hatching eggs for more than 7 days seems to negatively affect the hatching percentage and embryonic development (Fasenko, 2007). Addo et al. (2018) also explained that the extended storage of chicken eggs beyond seven days is harmful to chicken quality and hatchability. Reirink et al. (2010) and King'ori (2011) emphasized that egg storage duration reduces hatchability and chicken quality. The higher embryonic mortality of eggs that were stored for a longer period was observed in a study that was conducted by Fasenko (2007). Lima et al. (2012) also reported higher embryo mortality in eggs that were stored for 14 days before incubation. Prolonged egg storage (14 days) resulted in chickens with unhealed 
navels, deformities, and general symptoms of weakness (Fasenko, 2009). In addition, Yassin et al. (2008) clarified that pre-incubation egg storage for a long time adversely affects the chicken embryonic development due to reduced egg quality. Moreover, Reirink et al. (2010) stated that the chickens that are deformed at hatching may die within two days after hatching.

Currently, farmers who are engaged in Koekoek chicken's hatching industry have been facing a problem of lower hatchability. The reason is that there has been no study addressing pre-incubation egg storage length since the introduction of Koekoek chickens in Lesotho. Therefore, the current study aimed to determine the effect of egg storage length on hatchability and survival of Koekoek chickens up to seven days after hatching.

\section{MATERIALS AND METHODS}

\section{Ethical approval}

The research and ethics committee in the Department of Animal Science of the National University of Lesotho approved the current study based on international welfare standards for use of animals in conducting research.

\section{Study site}

The study was conducted at the Department of Animal Science Experimental farm of the National University of Lesotho which is located $36 \mathrm{~km}$ from Maseru, the capital city of Lesotho.

\section{Management of chickens}

Koekoek chickens were given laying mash bought from the commercial feed manufacturer with the following chemical composition (Table 1).

Table 1. Nutrient composition of Koekoek chickens laying mash at the age of 18 to 32 weeks

\begin{tabular}{lc}
\hline Nutrients & Ingredient $(\mathbf{g} / \mathbf{k g})$ \\
\hline Crude protein & 130.0 \\
Moisture & 120.0 \\
Fiber & 70.0 \\
Calcium (minimum) & 27.0 \\
Calcium (minimum) & 45.0 \\
Phosphorus & 5.0 \\
Methionine & 0.5 \\
Lysine & 0.8 \\
Metabolizable Energy $(\mathrm{Kcal} / \mathrm{kg})$ & 2900 \\
\hline
\end{tabular}

The feed and water were prepared ad libitum daily. They were raised in a deep litter system with a floor space of $0.25 \mathrm{~m}^{2}$ per chicken. The house was constructed in a way that there was ventilation. The artificial light and heat were not provided for chickens. All Koekoek chickens were given a stress pack dissolved in water on arrival. Those Koekoek chickens that presented signs of illness were isolated and treated accordingly.

\section{Experimental design}

Eggs were collected from 150 Koekoek hens aged 3032 weeks in the morning and afternoon. In each rearing pen, there were 10 hens and 1 cock. The study was conducted for a period of 42 days from February to March 2020. A total of 400 eggs were collected and cleaned using damp cloths immersed in warm water to avoid alterations in the egg embryo. The eggs were checked for any cracks, abnormal shapes, spots, and transparent markings before being put in the trays for storage. Eggs weighing between 50 and $55 \mathrm{~g}$ were candled using a led torch to ensure that the fertile ones were used as experimental units. The eggs were stored in a house with opened windows during the day for ventilation purposes. The collected eggs were stored for 3, 7, and 11 days before being taken to the sure hatch incubator (SH680, automatic digital model, South Africa) for 21 days. The incubator was turned on for 24 hours before eggs were placed inside. The humidity was $70 \%$ and the temperature was $37.6^{\circ} \mathrm{C}$. A total number of 270 eggs were allotted to three different treatment groups through a completely randomized design and each treatment was replicated three times with 30 eggs per replicate.

\section{Data collection}

On day 22, unhatched eggs were removed from the incubator and were broken to check the stage at which chicken embryonic development was stopped based on the guidelines provided by Hamburger and Hamilton (1951). The chicken embryonic mortality was recorded as early embryonic (1-5 days), mid embryonic (6-10 days), and late embryonic (15-21days) mortality. The hatching percentage was calculated as follows:

Hatching $(\%)=\frac{\text { Total number of eggs hached }}{\text { Total number of fertile eggs incubated }} \times 100$

After hatching the chicken mortality was observed for seven days.

\section{Statistical analysis}

The data were analyzed using the Statistical Package for Social Sciences (SPSS, version 20). General Linear Model Univariate was used to establish the effect of preincubation egg storage duration on egg hatchability and 
survival of hatched Koekoek chickens. The differences between treatments were tested by Duncan's new multiple range test. In all the analyses, the confidence level was at $95 \%$ while the threshold for significance level was $\mathrm{p}<$ 0.05 .

\section{RESULTS AND DISCUSSION}

\section{Egg hatchability}

As can be seen in Table 2, the hatching percentages were $87.33,78.67$, and 71 for eggs that were stored for 3 , 7 , and 11 days, respectively. It could be concluded that eggs that were stored for three days before incubation had a higher hatching percentage $(\mathrm{p}<0.05)$ followed by those that were stored for 7 days. The hatchability of eggs that were stored for at least 11 days before incubation was $16.33 \%$ and $8.66 \%$, less than those stored for three and seven days, respectively.

Table 2. Hatching percentage of Koekoek eggs stored for 3,7 , and 11 days.

\begin{tabular}{lcc}
\hline Treatment & Hatching percentage & S.E \\
\hline 3 days & $87.33^{\mathrm{a}}$ & 4.54 \\
7 days & $78.67^{\mathrm{b}}$ & 2.15 \\
11 days & $71.00^{\mathrm{c}}$ & 3.81 \\
\hline
\end{tabular}

abc Means within a column without common superscript differ significantly $(\mathrm{p}<0.05)$, S.E: Standard Error.

A similar trend of results was recorded by Ayeni et al. (2020) who indicated that the elongated storage of eggs reduced hatchability and increased the amount of incubation time required for hatching. Khan et al. (2014) also illustrated that storing eggs beyond 7 days resulted in a hatching percentage of 33.89 . The studies that were performed on Japanese quail presented that the extended period of egg storage before incubation resulted in lower hatchability (Lacin et al., 2008; Mani et al., 2008; Seker et al., 2005). Furthermore, Romao (2008) reported that excessive egg storage duration can adversely affect hatchability. In support of the results obtained from the current study, Senbeta (2016) indicated that the eggs that were stored for the shortest period ( 5 days) had the largest hatchability rate. On the other hand, Petek and Dikmen (2006) explained that the hatchability of fertile eggs was not significantly affected by the length of the egg storage period. In addition, Günhan and Kirikçi (2017) explained that storage time did not affect the hatchability of fertile eggs.

\section{Embryonic mortality}

The findings of the current study indicated that eggs stored for more than seven days before incubation had higher embryonic mortality (Table 3 ). The mid and late embryonic deaths were significantly lower in eggs that were stored for three days $(\mathrm{p}<0.05)$ and mid and late embryonic death was higher for those that were stored for 11 days before incubation $(p<0.05)$. Generally, egg storage for three days before incubation could reduce embryonic mortality by $68.35 \%$ and $128.88 \%$ than storage periods of 7 and 11 days prior to incubation, respectively.

Table 3. Embryonic mortality of Koejoek eggs stored for 3,7 , and 11 days.

\begin{tabular}{lllllll}
\hline Treatments & EEM & SE & MEM & SE & LEM & SE \\
\hline 3 days & $4.07^{\mathrm{a}}$ & 2.35 & $3.00^{\mathrm{a}}$ & 1.05 & $5.60^{\mathrm{a}}$ & 1.20 \\
7 days & $5.00^{\mathrm{a}}$ & 3.00 & $5.60^{\mathrm{b}}$ & 1.98 & $10.73^{\mathrm{b}}$ & 0.83 \\
11 days & $7.33^{\mathrm{a}}$ & 1.56 & $6.67^{\mathrm{b}}$ & 0.95 & $15.00^{\mathrm{c}}$ & 1.45 \\
\hline $\begin{array}{l}\text { abc Means within } \\
\text { significantly (p column without common }\end{array}$ & superscript & differ \\
mortality, MEM: & Mid emb: Standard Error, EEM: Early embryonic \\
mortality.
\end{tabular}

In support of the results obtained from the present study, Grochowska et al. (2019) indicated that early embryonic mortality increased with the lengthening of egg storage time. Similarly, Fasenko (2007) emphasized that long-term egg storage induces cell death, and hence, higher embryonic mortality. Fasenko (2007) also reported the negative effect of long egg storage on embryonic development and metabolism. In order to reduce the chicken embryonic mortality in eggs stored for more than seven days before incubation, Tag EL-Din et al. (2017) recommended that eggs should be warmed for 2.5 hours after every five days. In the same vein, Khan et al. (2014) reported more embryonic deaths in eggs that were stored for at least eight days. Schmidt (2009) also reported a linear relationship between storage time and embryonic mortality in chickens. In a study conducted by Nasri et al. (2019), it was discovered that the pre-incubation egg storage of more than seven days has a negative impact on the internal egg quality and embryonic survival during the storage and incubation period. The same results were shared by Petek and Dikmen (2006) who found that egg storage for three days can result in a satisfactory hatching percentage in quails. The embryos of eggs stored for nine days revealed lower hatchability and higher mortality during incubation (Khan et al., 2014). The longer storage period significantly increased late embryonic mortality (Gómez-de-Travecedo et al., 2014). Other researchers 
reported that storing eggs longer than seven days before incubation is accountable for slowing and damaging embryonic development and livability (Elibol et al., 2002; Christensen et al., 2001). On the other hand, Sujata et al. (2019) reported that pre-incubation egg storage did not affect the embryonic throughout all the stages of embryonic development. Fasenko et al. (1992) also observed that egg storage duration did not affect embryonic mortality.

\section{Chickens' mortality}

As can be seen in Table 4, indicated that the survival rate of hatched chickens from eggs stored for three days was significantly higher, compared to hatched chickens from eggs stored for 7 and 11 days ( $p>0.05$ ). In support of results from the current study, Addo et al. (2018) highlighted that prolonged egg storage beyond 7 days is detrimental to chicken quality. In a study performed by Fasenko (2007) chickens with unhealed naves, deformities, and signs of weakness were hatched from eggs that were stored for more than 14 days. Nasri et al. (2019) also stipulated that prolonged egg storage duration resulted in lower chicken quality in both young and old breeders because storage duration has been shown to affect egg quality and have adverse effects on embryonic development and post-hatch performance. These findings were in agreement with Petek and Dikmen (2006) who reported that egg storage for more than seven days deteriorated post-hatch performance and chicken quality. On other hand, El-Sagheer (2012) reported that the number of chickens' deaths was not significantly affected by the pre-incubation storage period.

Table 4. The mortality rate of Koekoek chickens hatched from eggs stored for 3, 7, and 11 days

\begin{tabular}{lcc}
\hline Treatments & $\begin{array}{c}\text { Chick mortality } \\
(\%)\end{array}$ & $\begin{array}{c}\text { Standard } \\
\text { Error }\end{array}$ \\
\hline 3 days & $7.33^{\mathrm{a}}$ & 1.92 \\
7 days & $11.33^{\mathrm{b}}$ & 2.56 \\
11 days & $11.67^{\mathrm{b}}$ & 1.54
\end{tabular}

ab Means within a column without common superscript differ
significantly $(\mathrm{p}<0.05)$.

\section{CONCLUSION}

The pre-incubation storage of Koekoek eggs for a maximum period of three days improved the hatching percentage, embryonic survival as well as post-hatch chicken survival. Therefore, it is recommended that farmers should not store eggs for longer than three days to improve the reproductive performance of Koekoek chickens.

\section{DECLARATIONS}

\section{Authors' contribution}

Setsumi Motsoene Molapo conceptualized and wrote the manuscript. Motselisi Mahlehla contributed to data collection and statistical analysis. Paseka Pascalis Kompi collected data and designed the graphics. Monaheng Taoana collected data and drafted the manuscript. All authors read and approved the final manuscript.

\section{Competing interests}

The authors have not declared any conflict of interest.

\section{Acknowledgments}

All authors would like to acknowledge the Department of Animal Science of the National University of Lesotho for funding this research.

\section{REFERENCES}

Abadi T, Gebretsadik D, Gebremedhin K, Tsigab T, Zenebe M and Desta D (2020). On-farm Evaluation and Demonstration of Koekoek chicken under farmers' condition in north western Tigray, Ethiopia. International Journal of Veterinary Science and Research, 6 (1): 6467. DOI: https://dx.doi.org/10.17352

Addo A, Hamidu JA, Ansah AY and Adomako K (2018). Impact of Egg Storage Duration and Temperature on Egg Quality, Fertility, Hatchability and Chick Quality in Naked Neck Chickens. International Journal of Poultry Science, 17: 175-183. DOI: https://www.doi.org/10.3923/ijps.2018.175.183

Ayeni AO, Agbede JO and Igbasan FA (2020). Effects of storage periods and positioning during storage on hatchability and weight of the hatched chicks from different egg sizes. Bulletin of the National Research Centre, 44: 101. DOI: https://doi.org/10.1186/s42269$\underline{020-00362-4}$

Belay S, Mehari R, Gebrechristos H and Haileslassie A (2018). Production performance evaluation of koekoek chicken under farmer management practice in Tigray region, northern Ethiopia. International Journal of Livestock Production, 9 (9): 232-237. DOI: https://doi.org/10.5897/IJLP2017.0436

Boleli ICI, Morita VS, Matos JB, Thimotheo MI and Almeida VR (2016). Poultry Egg Incubation: Integrating and Optimizing Production Efficiency. Brazilian Journal of Poultry Science, 2: 116. DOI: http://dx.doi.org/10.1590/1806-9061-2016-0292

Christensen VL, Grimes JL, Wineland MJ and Bagley LG (2001). Effects of turkey breeder hen age, strain, and length of the incubation period on survival of embryos and hatchlings. Journal of Applied Poultry Research, 10 : 5-15. DOI: https://doi.org/10.1093/japr/10.1.5

Elibol O, Peak SD and Brake J (2002). Effect of flock age, length of egg storage, and frequency of turning during storage on hatchability of broiler hatching eggs Poultry Science, 81(7): 945-950. DOI: https://doi.org/10.1093/ps/81.7.945

El-sagheer M (2012). Influence of preincubation storage duration on egg quality, hatchability, embryonic mortality and viability of 
Dandarawi chicks. Egyptian Journal of Animal Production, 49(2): 173-180. http://www.aun.edu.eg/uploaded full txt/14580 full txt.pdf

Fasenko GM, Robinson FE and Christensen VL (2009). Effect of long term storage on the egg, embryo and chick. Avian Biological Research, 2: 73-79. DOI: https://doi.org/10.3184\%2F175815509X431858

Fasenko GM (2007). Egg storage and the embryo. Poultry Science, 86 (5): 1020-1024. DOI: https://doi.org/10.1093/ps/86.5.1020

Fasenko GM, Hardin RT, Robinson FE and Wilson JL (1992). Relationship of hen age and egg sequence position with fertility, hatchability, viability, and pre-incubation embryonic development in broiler breeders. Poultry Science, 71 (8): 13741383. DOI: https://doi.org/10.3382/ps.0711374

Gómez-de-Travecedo P, Caravaca F and González-Redondo P (2014). Effects of storage temperature and length of the storage period on hatchability and performance of red-legged partridge (Alectoris rufa) eggs. Poultry science,93(3): 747-54. DOI: https://doi.org/10.3382/ps.2013-03329

Grochowska E, Kinal A, Sobek Z, Siatkowski I and Bednarczyk M (2019) Field study on the factors affecting egg weight loss, early embryonic mortality, hatchability, and chick mortality with the use of classification tree technique. Poultry Science, 98(9): 3626-3636. DOI: https://doi.org/10.3382/ps/pez180

Günhan Ş and Kirikçi K (2017). Effects of different storage time on hatching results and some egg quality characteristics of rock partridge (A. graeca) (management and production). Poultry Science, 96 (6):1628-1634. DOI: https://doi.org/10.3382/ps/pew443

Hamburger V and Howard LH (1951). A Series of Normal Stages in the Development of the Chick Embryo. Journal of Morphology, 88: 49-92. DOI: https://doi.org/10.1002/jmor.1050880104

Khan MJA, Khan SH, Bukhsh A and Amin M (2014). The effect of storage time on egg quality and hatchability characteristics of Rhode Island Red (RIR) hens. The Journal Veterinarski arhiv, 84: 291-303. http://wwwi.vef.hr/vetarhiv/papers/2014-84-3-8.pdf

King'ori AM (2011). Review of the factors that influence egg fertility and hatchability in poultry. International Journal of Poultry Science, $10(6)$ :

DOI: https://doi.org/10.3923/ijps.2011.483.492

483-492.

Lacin E, Yildiz A, Esenbuga N and Macit M (2008). Effects of differences in the initial body weight of groups on laying performance and egg quality parameters of Lohmann laying hens. Czech Journal of Animal Science. 53: 466-471. DOI: https://doi.org/10.17221/341-CJAS

Lima JCS, Silva P, Coelho LR, Borges, MS, Freitas A, Fonseca B (2012). Effects of Inverting the Position of Layers Eggs During Storage on Hatchery Performance Parameters. Brazilian Journal of Poultry Science. 14. 245-248. DOI: https://doi.org/10.1590/S1516$\underline{635}$

Mani AU, Garndawa II and Usman BA (2008). Effects of Pre-Incubation Storage on the Hatchability of Quail (Coturnix coturnix japonica) Eggs in the Sahel Region of Nigeria. International Journal of Poultry Science, 3(4): 350-354. DOI: https://doi.org/10.3923/ijps.2008.350.354

Molapo SM and Kompi P (2015). The Effect of Cock: Hen Ratio on Reproduction Performance of Koekoek Chickens in the Lowlands of Lesotho. Theriogenology Insight, 5(2): 139-145. DOI: https://doi.org/10.5958/2277-3371.2015.00015.7
Nasri H, Brand H, Najar T and Bouzouaia M (2019). Egg storage and breeder age impact on egg quality and embryo development. Journal of Animal Physiology and Animal Nutrition, 104(2): 1-12. DOI: https://doi.org/10.1111/jpn.13240

Petek M and Dikmen S (2006). The effects of prestorage incubation and length of storage of broiler breeder eggs on hatchability and subsequent growth performance of progeny. Czech Journal of Animal Science, 51(2): 73-77. DOI: https://doi.org/10.17221/3912CJAS

Reijrink IAM, Berghmans D, Meijerhof R, Kemp B and Van den Brand $H$ (2010). Influence of egg storage time and pre incubation warming profile on embryonic development, hatchability, and chick $\begin{array}{llll}\text { quality. } & \text { Poultry } \quad \text { Science, } 89 & \text { (6):1225-1238. }\end{array}$ DOI: https://doi.org/10.3382/ps.2009-00182

Romao J, Moraes TGV, Teixeira RSC, Cardoso WM and Buxade C (2008). Effect of Egg Storage Length on Hatchability and Weight Loss in Incubation of Egg and Meat Type Japanese Quails. Brazilian Journal of Poultry Science, 10(3): 143-147. DOI: https://doi.org/10.1590/S1516-635X2008000300001

Salamon A (2020). Fertility and Hatchability in Goose Eggs: A Review. International Journal of Poultry Science, 19: 51-65. DOI: https://doi.org/10.3923/ijps.2020.51.65

Schmidt GS, Figueiredo EAP, Saatkamp MG and Bomm ER (2009). Effect of storage period and egg weight on embryo development and incubation results. Brazilian Journal of Poultry Science, 11(1):1-5. DOI: $\quad$ https://doi.org/10.1590/S1516$\underline{635 \times 2009000100001}$

Seker I, Kul S and Bayraktar M (2005). Effects of storage period and egg weight of Japanese quail eggs on hatching results (short communication). Archiv fur Tierzucht. 48(5): 518-526. DOI: https://doi.org/10.5194/aab-48-518-2005

Senbeta EK (2016). Effect of Egg Storage Periods on Egg Weight Loss, Hatchability and Growth Performances of Brooder and Grower Leghorn Chicken. IOSR Journal of Agriculture and Veterinary $\begin{array}{llll}\text { Science } & \text { (IOSR-JAVS), } & \text { 9(11): }\end{array}$ DOI: https://doi.org/10.9790/2380-0911017579

Sujata D, Rajarshi S, Subhransu P, Bikas D and Asish D (2019). Factors Associated with Embryonic Mortality of Eggs of Vanaraja Breeder Chicken Reared on Deep Litter System. International Journal of Current Microbiology and Applied Sciences, 8(4): 525-532. DOI: https://doi.org/10.20546/ijcmas.2019.804.057

Tag-el-Din H T, Kalaba ZM, El-Kholy K and Abd-El-Maksoud S (2017). Effect of Short Period Incubation During Egg Storage on Hatchability, Embryonic Mortality and Chick Quality. Journal of Animal and Poultry Production. Mansoura University, 8(7): 161165. DOI: https://doi.org/10.21608/jappmu.2017.45841

Wong JT, de Bruyn J, Bagnol B, Grieve H, Li M, Pym R and Alders RG (2017). Small-scale poultry and food security in resource-poor settings: A review, Global Food Security, 15: 43-52. DOI: https://doi.org/10.1016/j.gfs.2017.04.003

Yassin H, Velthuis AGJ, Boerjan M, Van Riel J and Huirne RBM (2008). Field study on broiler eggs hatchability. Poultry Science, 87(11): 2408-2417. DOI: https://doi.org/10.3382/ps.2007-00515

Yirgu T, Tesfaye E, Amare A and Alewi M (2019). On-Farm Evaluation and Demonstration of Dual Purpose Chicken"Potchefstroom koekoek" Technology Packages in Sidama Zone, Ethiopia. World Journal of Agricultural Sciences, 15: 317-323. DOI: https://doi.org/10.5829/idosi.wjas.2019.317.323 